\title{
ESR en IPSAS: Harmonisering van financiële verslaggeving door overheden
}

\section{Frans van Schaik en Léonard Haakman}

SAMENVATTING De Europese statistische regels voor overheden, van belang voor onder andere het bepalen van tekort en schuld volgens de EMU-normen, en internationale jaarrekeningregels van overheden, hebben vele overeenkomsten: het zijn beide baten-lastenstelsels en ze brengen verslag uit over dezelfde transacties en gebeurtenissen. Ze hebben echter verschillende doelstellingen waardoor sommige transacties en gebeurtenissen anders worden verwerkt. In dit artikel analyseren we de overeenkomsten en verschillen tussen de statistische grondslagen van het Europese Systeem van Nationale en Regionale Rekeningen (ESR) en de jaarrekeningregels van de International Public Sector Accounting Standards (IPSAS) Board. Met deze analyse beogen we een bijdrage te leveren aan het begrip van de financiële informatie die overheden openbaar maken, hetgeen van groot belang is in deze tijd van schuldencrisis. Daarbij komen we tot de conclusie dat de jaarrekeningen van overheden opgesteld volgens algemeen geaccepteerde verslaggevingsregels en voorzien van een verklaring van een rekenkamer of accountant een belangrijke bijdrage kunnen leveren aan de totstandkoming van de statistieken over de overheidsfinanciën, en daarmee aan de monitoring van de financiële positie van de Europese lidstaten door de Europese Commissie.

\section{RELEVANTIE VOOR DE PRAKTIJK De schuldencrisis van de overheden binnen de Euro-} pese Unie heeft ertoe geleid dat er grote belangstelling is ontstaan voor de financiële positie van de overheden van Europese lidstaten en voor transparante verslaglegging hierover. Hoe verschilt het ESR, het statistische stelsel dat overheden in Europa volgen om elkaar financieel de maat te nemen, van het verslaggevingsstelsel IPSAS, en welke bijdrage kan IPSAS leveren aan goede statistieken?

\section{Inleiding}

Financiële informatie van overheden is beschikbaar in de vorm van statistische informatie en in de vorm van jaarrekeningen. Deze informatie is deels aanvullend en deels overlappend.
De Europese Unie heeft de lidstaten de verplichting opgelegd om statistische informatie over de overheidsfinanciën te verstrekken volgens het Europees Systeem van Nationale en Regionale Rekeningen (ESR). ${ }^{1}$ Deze informatie wordt onder meer gebruikt om de tekorten en de schulden van lidstaten te monitoren en te toetsen aan de EMUnormen. De EMU-normen stellen dat een land geen hoger overheidstekort dan 3 procent van het bruto binnenlands product (bbp) mag hebben, en geen schuld die hoger is dan 60 procent van het bbp. De statistische informatie wordt in Nederland opgesteld door het Centraal Bureau voor de Statistiek (CBS).

$\mathrm{Na}$ het constateren van de fouten in de Griekse statistische rapportages over overheidstekort en -schuld heeft de Europese Commissie aandacht besteed aan de bronnen van de statistische rapportages. Aan de verkeerde cijfers van Griekenland lag namelijk niet alleen malversatie ten grondslag, maar ook een gebrek aan betrouwbare jaarverslaglegging van de overheid. De Europese Commissie heeft daarom maatregelen genomen om de betrouwbaarheid van de financiële gegevens van de overheid - zowel vanuit de jaarverslaglegging als vanuit de statistiek - te verbeteren. Deze maatregelen zijn onderdeel van een pakket van vijf verordeningen en een richtlijn ${ }^{2}$ die de Europese Raad eind 2011 heeft vastgesteld. In artikel 3 van deze Europese richtlijn staat dat alle overheden verslagleggingsstelsels moeten hanteren die voorzien in de statistische data op baten-lastenbasis conform het ESR. Tevens is opgenomen dat de verslaglegging onderwerp moet zijn van interne controle en externe audits. Verder stelt lid 3 van artikel 16 van deze richtlijn dat eind 2012 de Europese Commissie zal beoordelen of IPSAS geschikt is voor de lidstaten. In een conceptresolutie van het Europese Parlement van 6 mei 2011 stond er nog dat lidstaten binnen drie jaar na inwerkingtreding van de richtlijn IPSAS moeten hanteren. 
Voor de opstelling van de jaarrekeningen van de overheden van de lidstaten gaf de Europese Unie voorheen geen voorschriften. De lidstaten kennen veel verschillende jaarverslagleggingsvoorschriften. Maar ook binnen een lidstaat hanteren de verschillende overheidslagen elk weer eigen verslagleggingsregels. De Comptabiliteitswet geeft voorschriften voor de opstelling van de jaarverslagen van het Rijk. Met de jaarverslagen van de ministeries leggen de ministers verantwoording af aan de Tweede Kamer. Het Financiële Jaarverslag van het Rijk dat de minister van Financiën op de derde woensdag van mei aan de Tweede Kamer aanbiedt, geeft het geaggregeerde beeld van het Rijk. Provincies en gemeenten kennen het Besluit Begroting en Verantwoording (BBV) waarin de voorschriften voor jaarrekening, begroting en statistiek zijn vastgelegd. Het Waterschapsbesluit geeft de voorschriften voor de jaarrekening en de statistische informatie van waterschappen. Voor andere overheidsinstellingen zoals scholen gelden de regels van boek 2, titel 9 van het Burgerlijk Wetboek aangevuld met voorschriften van de Raad voor de Jaarverslaggeving.

In Nederland passen de ministeries het verplichtingenkasstelsel toe, een variant van het kasstelsel waarbij rekening wordt gehouden met aangegane verplichtingen. De meeste overheidsinstellingen passen het baten-lastenstelsel toe, zoals gemeenten, provincies en waterschappen. Het kasstelsel wordt eigenlijk alleen nog toegepast bij een deel van de ministeries: de kerndepartementen. De afgelopen decennia zijn steeds meer taken van de ministeries ondergebracht in baten-lastendiensten, zoals Rijkswaterstaat en de RDW, in zelfstandige bestuursorganen, zoals het UWV en de SVB, en bij andere rechtspersonen met een wettelijke taak (RWT's), zoals onderwijsinstellingen. De baten-lastendiensten, de zelfstandige bestuursorganen (ZBO's) en de RWT's passen alle het baten-lastenstelsel toe. Het baten-lastenstelsel heeft dus ook in Nederland de laatste decennia duidelijk terrein gewonnen.

Voor een analyse van de thans geldende verslaggevingsregels voor het rijk en de lagere overheden in Nederland verwijzen we naar Dees, Budding, Van Schaik en Van Tiel (2009). Andere artikelen behandelen de verschillen tussen IPSAS en de verslaggevingsstelsels toegepast binnen de Nederlandse publieke sector, zoals het verslaggevingsstelsel van Nederlandse gemeenten en provincies (Van Schaik, 2007), het verslaggevingsstelsel van waterschappen (Van Schaik, 2009) en de Richtlijnen voor de Jaarverslaggeving (Van Schaik en Manschot, 2010), die onder andere worden toegepast door baten-lastendiensten. Uit deze artikelen blijkt dat de Nederlandse overheden IPSAS niet volgen maar onderling sterk verschillende verslaggevingsstelsels toepassen waardoor onderlinge vergelijkbaarheid beperkt is.

De International Public Sector Accounting Standards $(\text { IPSAS })^{3}$ hebben de laatste jaren sterk aan belang gewonnen als stelsel van regels voor de opstelling van jaarrekening van overheden. IPSAS beoogt de standaardisering van verslaggevingsstandaarden van overheden in de wereld.

Dit artikel is als volgt opgebouwd. Eerst schetsen wij kort de achtergrond van het ESR (paragraaf 2) en IPSAS (paragraaf 3). In paragraaf 4 geven wij een overzicht van de overeenkomsten (4.1) en verschillen (4.2) tussen ESR en IPSAS, gevolgd door een conclusie.

\section{ESR: een korte achtergrond}

Het Europese Systeem van Nationale en Regionale Rekeningen (ESR) geeft richtlijnen voor de opstelling van nationale rekeningen in Europa. Het systeem van nationale rekeningen geeft een kwantitatieve beschrijving van het economische proces binnen een land en de economische relaties met het buitenland. Als onderdelen van het economisch proces worden onderscheiden productie, inkomensvorming, inkomensverdeling, bestedingen en financiering. De overheidssector is een van de sectoren in de economie die hierin apart wordt beschreven. De overheid is een belangrijke actor in de economie als producent en consument van goederen en diensten en bovenal als herverdeler van inkomen en vermogen.

Het ESR is een Europese uitwerking van de richtlijnen die wereldwijd gelden voor het samenstellen van de nationale rekeningen. Deze wereldwijde regels zijn vervat in het SNA (System of National Accounts) waarbij de Verenigde Naties een coördinerende rol hebben. De richtlijnen van het SNA zijn opgesteld en worden vernieuwd na brede internationale consultaties. ${ }^{4}$ Hier zijn statistische bureaus en centrale banken van individuele landen bij betrokken, evenals internationale organisaties als het Internationaal Monetair Fonds (IMF), de Organisatie voor Economische Samenwerking en Ontwikkeling (OESO), de Europese Centrale Bank (ECB) en het statistische bureau van de Europese Commissie, Eurostat. Hierdoor zijn ook andere belangrijke internationale standaarden voor statistieken van de overheidsfinanciën, zoals de Government Finance Statistics (GFS) van het IMF en de Revenue Statistics van de OESO, geharmoniseerd met het SNA en daarmee met het ESR. Bij het opstellen van de statistische regels wordt ook gekeken naar internationale verslagleggingsvoorschriften als IFRS en IPSAS en naar US GAAP.

De statistische informatie die lidstaten op basis van het ESR moeten leveren, is in Europa bij verordening vastge- 
legd. ${ }^{5}$ De nationale rekeningen bevatten de noodzakelijke informatie voor wetenschap en beleid. Het CPB gebruikt de nationale rekeningen onder meer voor zijn jaarlijkse Centraal Economisch Plan en Macro-Economische Verkenningen waarop de regering weer haar beleid voor het komende jaar baseert. Verder wordt ook de hoogte van de Europese afdrachten van lidstaten bepaald op basis van het bruto nationaal inkomen uit de nationale rekeningen.

De definities van tekort en schuld van de overheid voor de EMU-normen zijn ontleend aan het ESR, zij het dat er enkele kleine verschillen zijn met het ESR. Zo hanteert het ESR voor alle verhandelbare schuldtitels de marktwaarde, terwijl de EMU-norm dat de schuld niet hoger mag zijn dan 60 procent van het bruto binnenlands product (bbp), betrekking heeft op de nominale schuld. Verder tellen de overlopende schulden (vooruitontvangen en nog te betalen gelden) bij ESR wel en bij de EMU-normen niet mee in het schuldbegrip. Bij de invoering van de EMU-normen was de gedachte hierachter dat de overlopende schulden toen niet betrouwbaar konden worden geraamd, onder meer door de dominantie van het kasstelsel bij Europese overheden. Ook werd het effect op de overheidsschuld als beperkt ingeschat.

Het begrip overheidstekort toegepast in de EMU-norm van 3 procent van het bbp, wijkt ook iets af van het ESR. Het overheidstekort volgens de EMU-definitie is inclusief de rentestromen die worden uitgewisseld bij rentederivaten terwijl het ESR deze rentestromen als balansmutaties behandelt. Sommigen duiden het overheidstekort ten onrechte aan als een kascijfer. Dit heeft ermee te maken dat men bij de invoering van de EMU-normen ervoor heeft gekozen de investeringen als uitgaven te laten meetellen in het overheidssaldo. De overige transacties worden daarentegen gewoon op baten-lastenwijze verantwoord. De keuze om de investeringen mee te laten tellen in plaats van afschrijvingen heeft te maken met de kwaliteit van de ramingen van de afschrijvingen. Doordat overheden verschillende afschrijvingstermijnen voor hetzelfde activum kunnen hanteren is er moeilijk een betrouwbare raming te maken. In het ESR worden afschrijvingen wel geraamd op basis van eigen veronderstellingen over de kapitaalgoederenvoorraad.

De regels ten aanzien van de statistische rapportage over overheidstekort en -schuld aan de Europese Unie zijn in een aparte wet vastgelegd. ${ }^{6}$

Haakman (2009) geeft een nadere uiteenzetting van de verslaggeving over EMU-saldo en EMU-schuld.

\section{IPSAS: een korte achtergrond}

De International Public Sector Accounting Standards Board (IPSASB) is een onafhankelijk orgaan dat onder auspiciën van de International Federation of Accountants regels voor financiële verslaggeving opstelt voor overheden en overheidsinstellingen. Het doel is het ontwikkelen van standaarden voor financiële verslaggeving van hoge kwaliteit die leiden tot transparante en vergelijkbare informatie in de voor algemene doeleinden bestemde jaarrekening van organisaties in de publieke sector. De leden van de IPSASB zijn afkomstig van centrale en lokale overheden, rekenkamers, accountantskantoren, accountantsinstituten, ontwikkelingsbanken en universiteiten.

De IPSAS-standaarden zijn speciaal ontwikkeld voor de publieke sector, maar ze komen zoveel mogelijk overeen met die voor de private sector. De meeste IPSAS-standaarden zijn ontwikkeld met IFRS (International Financial Reporting Standards) als uitgangspunt. IFRS-standaarden zijn ontwikkeld voor ondernemingen en worden door de IPSASB aangepast voor de publieke sector. De IPSASB wijkt slechts af van IFRS-standaarden als daar publieke-sectorspecifieke redenen voor zijn. IPSAS worden dan ook wel aangeduid als de IFRS voor de publieke sector. De IPSAS-standaarden houden aldus volledig rekening met de specifieke karakteristiek, de eigenheid, van de publieke sector.

Diverse landen hanteren bij het opstellen van hun verslaggevingsrichtlijnen voor de publieke sector de IPSASstandaarden vrij nauwgezet. Dat geldt voor Australië, Nieuw-Zeeland, Zuid-Afrika en Zwitserland. De IPSAS zijn in deze landen geïncorporeerd in de nationale regelgeving. De nationale regelgevers kennen daarbij weer een eigen due process, waarbij commentaren op ontwerpstandaarden worden verwerkt. Daardoor ontstaan hier en daar afwijkingen van IPSAS. De intergouvernementele organisaties stellen inmiddels bijna allemaal hun jaarrekening op volgens IPSAS. Dat geldt voor de Europese Unie, de OECD, NAVO en VN-organisaties. De Wereldbank en het IMF stimuleren de toepassing van IPSAS bij landen en geven daarbij financiële ondersteuning. De Europese Commissie bevordert de invoering van IPSAS binnen de Europese Unie, met name bij de recent toegetreden lidstaten.

Bij de ontwikkeling van IPSAS streeft de IPSASB naar convergentie met de internationale richtlijnen voor het samenstellen van nationale rekeningen van het SNA en het ESR, en de statistieken van de overheidsfinanciën van het IMF. Keuning en Van Tongeren (2004) behandelen het verband tussen de jaarrekening van de overheid en de nationale rekeningen. 


\section{Overeenkomsten en verschillen tussen ESR en IPSAS}

Het ESR en IPSAS hebben beide als doel inzicht te geven in de financiële situatie van de overheid. Het ESR is bedoeld als coherent raamwerk voor macro-economische analyses en voor verantwoording over tekort en staatsschuld door de Europese lidstaten aan de Europese Commissie. De doelstellingen van de jaarrekening volgens IPSAS zijn het afleggen van verantwoording door de overheid en besluitvorming.

Statistische informatie wordt niet gecontroleerd door rekenkamer of accountants. Alleen de gegevens over tekort en staatschuld worden geverifieerd door Eurostat. Jaarrekeningen opgesteld volgens IPSAS zijn veelal object van controle door rekenkamer of accountant.

\subsection{Overeenkomsten tussen ESR en IPSAS}

ESR en IPSAS vertonen sterke overeenkomsten omdat beide baten-lastenstelsels zijn; beide kennen een balans en laten transacties en waardeveranderingen tot uitdrukking komen in het jaar waarop ze betrekking hebben. Het feit dat beide stelsels baten-lastenstelsels zijn biedt waarborgen dat gecontroleerde jaarrekeningen volgens IPSAS kunnen worden gebruikt als betrouwbare input voor de statistieken van de overheidsfinanciën volgens ESR. Omdat zowel het ESR als IPSAS baten-lastenstelsels zijn is de rapportagestructuur van het ESR en IPSAS soortgelijk. Zo kennen beide een balans (overzicht van financiële positie) en een staat van baten en lasten. Het ESR laat ook zien hoe de balansstanden veranderen: als gevolg van transacties of prijsmutaties of overige volumemutaties. IPSAS kent het mutatieoverzicht van het eigen vermogen.

Veel bepalingen uit het ESR zijn in overeenstemming met IPSAS. Om de verschillen tussen de nationale rekeningen en de IPSAS-jaarrekeningen tot het noodzakelijke te beperken heeft afstemming plaatsgevonden tussen de IPSAS Board en de regelgevers voor de grondslagen van de natio- nale rekeningen, zoals IMF, VN en Eurostat (IPSAS Board, 2005). In 2010 is een werkgroep met eenzelfde samenstelling van start gegaan om de verslaggevingsregels voor de nationale rekeningen en IPSAS verder met elkaar in overeenstemming te brengen. Het Europees statistisch bureau Eurostat heeft naar aanleiding van de problematiek met Griekenland ook aangegeven dat invoering van IPSAS kan bijdragen aan het verbeteren van de kwaliteit van de statistieken van de overheidsfinanciën.?

Een van de verschillen tussen het ESR en IPSAS die na herziening van de ESR-regels in 2014 zal zijn verdwenen, is de verwerking van uitgaven an militair materieel en munitie. Werden deze onder ESR nog behandeld als aankoop van goederen en direct ten laste gebracht van het jaar van verwerving, vanaf 2014 wordt militair materiaal geactiveerd als vaste activa en gaandeweg ten laste gebracht van het jaar van gebruik. Munitie wordt als voorraad opgenomen en pas bij gebruik als last verwerkt. Deze behandeling komt overeen met de behandeling volgens IPSAS.

IPSAS biedt voor diverse verslaggevingsonderwerpen alternatieven, waarvan er één nagenoeg in overeenstemming is met ESR. In tabel 1 geven wij hiervan een overzicht op hoofdlijnen. In de volgende paragrafen geven we daarop een toelichting. Door in IPSAS steeds de ESR-conforme keuze te maken komen beide stelsels sterk overeen. Dit blijkt wel uit de jaarrekening van de federale overheid van Australië, waarin de statistische informatie ten behoeve van de nationale rekeningen geheel is verwerkt in de jaarrekening die overigens nagenoeg geheel in overeenstemming met IPSAS is opgesteld.

Verslaggevende entiteit

De verplichte statistische informatie over de overheid volgens het ESR betreft de zogenaamde sector overheid. Deze bestaat uit het totaal van het Rijk, gemeenten, provincies,

\section{Tabel 1 Verslaggevingsonderwerpen waarvoor IPSAS alternatieven biedt waarvan één in overeenstemming met ESR}

\begin{tabular}{|l|l|l|l|}
\hline & & ESR (Europese Systeem van Nationale en Regionale Rekeningen) & IPSAS (International Public Sector Accounting Standards) \\
\hline 1 & Verslaggevende entiteit & $\begin{array}{l}\text { - Verplicht: Sector overheid, onderscheiden naar centraal (inclusief Rijk), } \\
\text { lokaal (gemeenten, provincies, etc.) en sociale fondsen (UWV, SVB, CVZ) } \\
\text { - Vrijwillig: Publieke sector (sector overheid plus overheidsbedrijven) }\end{array}$ & $\begin{array}{l}\text { - Verplicht: Verslaggevende entiteit consolideert alle entiteiten waarover } \\
\text { zij control (beslissende zeggenschap) heeft. Daartoe behoren niet water- } \\
\text { schappen, provincies en gemeenten, maar wel overheidsondernemingen. } \\
\text { - Vrijwillig: Informatie inzake sector overheid }\end{array}$ \\
\hline 2 & Deelnemingen & Waardering op marktwaarde, eventueel netto-vermogenswaarde & Waardering volgens equity-methode, kostprijs of reële waarde \\
\hline 3 & Materiële vaste activa & $\begin{array}{l}\text { Per balansdatum geldende marktprijzen. Waardeverandering door } \\
\text { afschrijving en overige volumemutaties (bijvoorbeeld vernietiging door } \\
\text { oorlogshandelingen) en prijsmutaties (herwaarderingen) }\end{array}$ & $\begin{array}{l}\text { Reële waarde of historische kosten. Waardevermindering door afschrijving } \\
\text { en impairment }\end{array}$ \\
\hline 4 & Financieringskosten & Opnemen als last in de periode waarin ze zijn gemaakt (lastenmodel) & $\begin{array}{l}\text { Lastenmodel of activeringsmodel: activering van de financieringskosten } \\
\text { die rechtstreeks zijn toe te rekenen aan een kwalificerend actief }\end{array}$ \\
\hline
\end{tabular}


waterschappen, gemeenschappelijke regelingen, socialeverzekeringsinstellingen en alle non-profitinstellingen die niet voor de markt werken en waarover de overheid control (beslissende zeggenschap) heeft. De statistische informatie over de sector overheid wordt gepresenteerd voor het totaal van de sector overheid en voor de onderdelen centrale overheid, lokale overheid en sociale fondsen. Hiernaast kent het ESR ook het begrip publieke sector. De publieke sector bestaat uit de sector overheid plus alle deelnemingen waarin de overheid beslissende zeggenschap (control) heeft. Statistische gegevens over de publieke sector zijn op dit moment niet verplicht gesteld.

Waar in de statistiek de gezamenlijkheid van overheden als rapportage-eenheid centraal staat, gaat IPSAS uit van een individuele verslaggevende overheidsentiteit. IPSAS consolideert alle entiteiten waarover deze verslaggevende overheidsentiteit control heeft. In IPSAS is opgenomen dat consolidatie is vereist als de entiteit die de jaarrekening opstelt control (overheersende zeggenschap) heeft over een andere entiteit, dat wil zeggen de macht heeft om het financiële en operationele beleid van een andere entiteit te bepalen om voordelen uit diens activiteiten te verkrijgen. Dit sluit dus goed aan op het begrip publieke sector van het ESR.

De verslaggevende entiteit Rijk heeft geen control over waterschappen, provincies en gemeenten, dus consolideert het Rijk deze niet. Het Rijk heeft wel control over overheidsondernemingen en de verslaggevende entiteit volgens IPSAS consolideert dus alle overheidsondernemingen van de rijksoverheid, inclusief bijvoorbeeld de centrale bank. Overheidsondernemingen zijn geen onderdeel van de sector overheid en worden dus niet opgenomen in de sector overheid conform het ESR, maar wel in de gegevens over de publieke sector.

IPSAS schrijft niet voor of ook financiële informatie over de sector overheid openbaar wordt gemaakt. Als financiële informatie over de sector overheid openbaar gemaakt wordt dan geeft IPSAS 22 Openbaarmaking van financiële informatie over de sector overheid daarvoor voorschriften. Indien financiële informatie over de sector overheid in de jaarrekening van overheden is opgenomen vormt dit een nuttige brug naar de statistische informatie over de sector overheid volgens het ESR. Zie Van Schaik (2008) voor een nadere uiteenzetting over consolidatie in de overheidsverslaggeving.

\section{Deelnemingen}

Het ESR waardeert deelnemingen op marktwaarde. Indien er geen marktwaarde bekend is staat het ESR toe de nettovermogenswaarde te registreren. Volgens IPSAS dienen deelnemingen te worden gewaardeerd volgens de equitymethode, tegen kostprijs of reële waarde (als financieel instrument). Bij de waardering tegen reële waarde spreekt IPSAS een voorkeur uit voor marktwaarde. Bij de equitymethode wordt de investering aanvankelijk opgenomen tegen kostprijs en later verhoogd of verlaagd met het aandeel van de overheid in de winst of het verlies van de deelneming na datum van overname.

\section{Materiële vaste activa}

Het ESR stelt de per balansdatum geldende marktwaarde (reële waarde) verplicht voor de waardering van materiële vaste activa. IPSAS biedt een keuzemogelijkheid tussen reële waarde (normaliter de marktwaarde vastgesteld door taxatie) en historische kosten. De waardeverandering van materiële vaste activa volgens het ESR komt tot stand door afschrijvingen en volume- en prijsmutaties. De afschrijvingen vormen daarbij als gebruik van vaste activa een last in het ESR. Volume- en prijsmutaties worden alleen via de balans geregistreerd. In IPSAS ontstaat waardevermindering door afschrijvingen en impairment.

\section{Financieringskosten}

Alle financieringskosten worden onder ESR als last genomen in de periode waarin ze zijn gemaakt (lastenmodel). IPSAS kent twee methoden: het lastenmodel overeenkomend met ESR en het activeringsmodel waarbij activering plaatsvindt van de financieringskosten die rechtstreeks zijn toe te rekenen aan de verwerving, bouw of productie van een kwalificerend actief.

\subsection{Verschillen tussen ESR en IPSAS}

Enkele verschillen blijven bestaan vanwege de verschillende doelstellingen van beide stelsels. De statistische grondslagen beogen een coherent raamwerk te vormen voor macro-economische analyses, terwijl een jaarrekening opgesteld volgens IPSAS als doel heeft om verantwoording af te leggen en om hierop besluitvorming te baseren.

Tabel 2 geeft een overzicht op hoofdlijnen van de verschillen tussen ESR en IPSAS.

\section{Rechten op ondergrondse minerale reserves}

$\mathrm{Bij}$ het ESR moeten bewezen reserves in principe worden geactiveerd en gewaardeerd worden tegen de contante waarde van verwachte toekomstige kasstromen. Wegens de grote marge bij het ramen van de contante waarde stelt het Europese statistische bureau Eurostat deze balanspost niet verplicht. Bij IPSAS voldoen winstrechten op ondergrondse minerale reserves veelal niet aan de eis van betrouwbare meetbaarheid en worden daarom meestal niet geactiveerd. 
Tabel 2 Verschillen op hoofdlijnen tussen ESR en IPSAS

\begin{tabular}{|l|l|l|l|}
\hline & & $\begin{array}{l}\text { ESR (Europese Systeem van Nationale en Regio- } \\
\text { nale Rekeningen) }\end{array}$ & $\begin{array}{l}\text { IPSAS (International Public Sector Accounting } \\
\text { Standards) }\end{array}$ \\
\hline 1 & Rechten op ondergrondse minerale reserves & $\begin{array}{l}\text { Bewezen reserves worden geactiveerd en gewaardeerd } \\
\text { op de contante waarde van verwachte toekomstige } \\
\text { kasstromen }\end{array}$ & $\begin{array}{l}\text { Voldoen veelal niet aan de eis van betrouwbare meet- } \\
\text { baarheid en worden dan niet geactiveerd }\end{array}$ \\
\hline 2 & Pensioenverplichtingen ambtenaren & $\begin{array}{l}\text { Stelsels met fondsvorming worden niet verantwoord op } \\
\text { de balans van de verheid. Stelsels zonder fondsvor- } \\
\text { ming worden verantwoord als contingent liabilities }\end{array}$ & $\begin{array}{l}\text { Bij defined benefit: opnemen als pensioenschuld op de } \\
\text { balans. Bij defined contribution: geen schuld op de } \\
\text { balans. }\end{array}$ \\
\hline 3 & Voorzieningen & Geen voorzieningen & $\begin{array}{l}\text { Voorzieningen worden gevormd voor verplichtingen die } \\
\text { waarschijlijik zullen worden afgewikkeld }\end{array}$ \\
\hline 4 & Publiek-private samenwerking & $\begin{array}{l}\text { Bepalend voor al dan niet activeren van het actief is } \\
\text { welke partij het overwegende economisch risico draagt }\end{array}$ & $\begin{array}{l}\text { Bepalend voor al dan niet activeren is de vraag of de } \\
\text { verslaggevende entiteit control heeft over het actief }\end{array}$ \\
\hline 5 & Winsten en verliezen op deelnemingen & $\begin{array}{l}\text { Vormen geen onderdeel van de staat van baten en } \\
\text { lasten, maar van de staat van overige balansmutaties }\end{array}$ & Worden verantwoord op de staat van baten en lasten \\
\hline
\end{tabular}

Pensioenverplichtingen ambtenaren

Het ESR vereist vanaf 2014 de vermelding van pensioenverplichtingen via omslagstelsels als de AOW als contingent liabilities. Pensioenverplichtingen van de eigen ambtenaren die via pensioenfondsen worden gefinancierd, vormen in de nationale rekeningen geen onderdeel van de sector overheid, maar van de sector pensioenen en verzekeraars. IPSAS verplicht tot het opnemen van pensioenverplichtingen als pensioenschuld op de balans. Gezien het ontbreken van een kapitaaldekkingsstelsel bij veel overheden heeft dit verschil tussen ESR en IPSAS een enorme impact op het getoonde eigen vermogen.

\section{Voorzieningen}

Het ESR kent geen voorzieningen voor de overheid. Bij IPSAS worden voorzieningen gevormd voor bestaande rechtens afdwingbare en bestaande feitelijke verplichtingen die waarschijnlijk zullen worden afgewikkeld. Kostenegalisatievoorzieningen zijn niet toegestaan.

Publiek-private samenwerking

Bij het ESR is bepalend voor het al dan niet activeren van het actief de vraag bij welke partij rekening en risico ligt (economische benadering). Bij IPSAS is bepalend voor het al dan niet activeren de vraag of de verslaggevende entiteit control heeft over het actief. Daardoor dienen soms onder het ESR bepaalde activa en de bijbehorende schuld te worden opgenomen op de balans en onder IPSAS niet of andersom.

Winsten en verliezen op deelnemingen

Winsten en verliezen op deelnemingen vormen geen onderdeel van het saldo van baten en lasten in het ESR. Zij worden volledig geboekt via de balans en de staat van overige mutaties. In IPSAS worden winsten en verliezen op deelnemingen verantwoord op de staat van baten en lasten en bepalen daarmee het overschot of tekort.

\section{Tot slot}

In dit artikel hebben we de overeenkomsten en verschillen geanalyseerd tussen het ESR en IPSAS. Door aanpassingen in het ESR en IPSAS zijn de twee stelsels elkaar de laatste jaren steeds verder naderbij gekomen. ESR en IPSAS vertonen sterke overeenkomsten omdat beide baten-lastenstelsels zijn: beide kennen een balans en laten transacties en waardeveranderingen tot uitdrukking komen in het jaar waarop ze betrekking hebben. Door in Europa steeds te kiezen voor de ESR-conforme optie in IPSAS kan IPSAS op de belangrijkste verslaggevingsonderwerpen nauw aansluiten op het ESR. Voorbeeld is de optie die IPSAS biedt om al dan niet informatie te verstrekken over de sector overheid. Door in Europa te kiezen voor het verplicht opnemen van informatie over de sector overheid, sluiten de IPSAS-cijfers qua verslaggevingsentiteit precies aan op het ESR.

Verschillen zijn inherent aan de verschillende doelstellingen van beide stelsels. Vanwege de sterke overeenkomsten is het aantal statistische aanpassingen beperkt. Bij het gebruiken van de IPSAS-jaarrekeningen voor de statistieken conform ESR kunnen deze verschillen bovendien relatief eenvoudig worden geëlimineerd, zoals bij voorzieningen en winsten en verliezen op deelnemingen. Het merendeel van de IPSAS-jaarrekeningen kan voor de statistiek ongewijzigd worden overgenomen omdat de algemene principes hetzelfde zijn. Aan een verdere harmonisering van de beide stelsels wordt gewerkt door een werkgroep van de IPSAS Board, Eurostat en andere internationale organisaties.

Ruimte voor interpretatie bestaat in elk verslaggevingsen statistisch stelsel. In de statistiek worden interpretatieverschillen geminimaliseerd door internationaal overleg 
gecoördineerd door Eurostat. Bij IPSAS kan dit binnen Europa op eenzelfde manier gestalte krijgen.

Jaarrekeningen van overheden opgesteld volgens internationale verslaggevingsstandaarden (IPSAS) en voorzien van een verklaring van een rekenkamer of accountant kunnen dus een belangrijke bijdrage leveren aan het verhogen van de kwaliteit van de nationale rekeningen opgesteld volgens ESR. Door het gebruik van IPSAS vormen de jaarrekeningen een betrouwbare input voor de statistieken van de overheidsfinanciën. Voor gebruikers wordt aldus optimale inzichtelijkheid van jaarrekening en statistische rapportage bereikt.
Prof. dr. F.D.J. (Frans) van Schaik RA is lid geweest van de International Public Sector Accounting Standards (IPSAS) Board van 2006-2011, is partner van Deloitte Accountants

B.V., en hoogleraar Management Accounting aan de

Universiteit van Amsterdam. Hij studeerde Econometrie,

Accountancy en Belastingkunde. E-mail:

fvanschaik@deloitte.nl.

Dr. L.P.A. (Léonard) Haakman is senior onderzoeker bij de afdeling Financiën van de Overheid van het Centraal Bureau voor de Statistiek en als projectleider verantwoordelijk voor de rapportages over overheidstekort en overheidsschuld aan de Europese Commissie. Hij studeerde Theoretische

Natuurkunde en Economie. E-mail: Ipa.haakman@cbs.nl.

\section{Noten}

ESR-handboek is vinden op: http://circa.europa.eu/irc/dsis/nfaccount/info/data/esa95/ esa95-new.htm.

2. Council directive 2011/85/EU of 8 November 2011 on requirements for budgetary frameworks of the Member States. Zie: http://eur-lex.europa.eu/LexUriServ/LexUriServ.do?uri=0J: L:2011:306:0041:0047:EN:PDF.

3. De volledige IPSAS-standaarden zijn te vinden op de website van de IPSAS Board: www.ipsasb.org.
In 2008 is een nieuwe versie verschenen van de richtlijnen van het SNA. De nieuwe voorschriften van het ESR, aangepast aan SNA 2008, zullen in 2014 ingaan.

5. Zie EU-verordening № 2223/96 van 25 juni 1996 en amendementen 1500/2000, 2516/ 2000, 2558/2001, 995/2001, 113/2002, 400/ 2009 .

6. Zie EU-verordening № 3605/1993 van 22 november 1993 en amendementen 475/2000, 351/2002, 2103/2005, 479/2009, 679/2010.
Communication from the Commission to the European Parliament and the Council 'Towards robust quality management for European Statistics', 15 april 2011. Zie: http://epp.eurostat.ec.europa.eu/portal/page/portal/quality/documents/COM-2011-211_Communication_Quality_Management_EN.pdf.

\section{Literatuur}

- Dees, M., G.T. Budding, F.D.J. van Schaik, T.A. van Tiel (2009), Externe verslaggeving van publieke organisaties, Den Haag: SDU Uitgevers.

- Haakman, L.P.A. (2009), Verslaggeving over EMU-saldo en EMU schuld, in: M. Dees, G.T. Budding, F.D.J. van Schaik, T.A. van Tiel (redactie), Externe verslaggeving van publieke organisaties (pp. 221-228), Den Haag: SDU Uitgevers.

- International Public Sector Accounting Standards Board (IPSASB) (2005), IPSAS and statistical bases of financial reporting: An analysis of differences and recommendations for convergence, Research report, januari 2005; zie: http://www.ifac.org/sites/default/ files/publications/files/international-publicsector.pdf
- International Public Sector Accounting Standards Board (IPSASB) (2011), Handbook of International Public Sector Accounting Standards Pronouncements, International Public Sector Accounting Standards Board (IPSASB), New York: International Federation of Accountants; zie: http://www.ifac.org/ publications-resources/2011-handbookinternational-public-sector-accountingpronouncements.

- Keuning, S. en T.A. van Tongeren (2004), The relationship between government accounts and national accounts, with special reference to Netherlands, Review of Income and Wealth vol. 50, no. 2 (juni), pp. 167-179.

- Van Schaik, F.D.J. (2007), Standaardisering van verslaggeving in de publieke sector. De verslaggevingsregels van gemeenten vergeleken met IPSAS, Maandblad voor
Accountancy en Bedrijfseconomie, vol. 81, no. 10 (oktober), pp. 462-468.

- Van Schaik, F.D.J. (2008), De consolidatiekring van overheden in Nederland, Maandblad voor Accountancy en Bedrijfseconomie, vol. 82, no. 11 (november), pp. 467-476.

- Van Schaik, F.D.J. (2009), Eigen verslaggevingsstelsel voor waterschappen beperkt vergelijkbaarheid, TPC Tijdschrift voor Public Governance, Audit \& Control, vol. 7, no. 3 (juni), pp. 35-39.

- Van Schaik, F.D.J. en D. Manschot (2010), Standaardisering van verslaggeving in de publieke sector. IPSAS vergeleken met de Nederlandse wet en de Richtlijnen voor de Jaarverslaggeving, Handboek Accountancy, oktober 2010, B.1.1245, pp. 1-48. 